\title{
Cerebral Hemodynamic Benefits after Contralateral Carotid Artery Stenting in Patients with Internal Carotid Artery Occlusion
}

\author{
F. Oka, H. Ishihara, S. Kato, M. Higashi, and M. Suzuki
}

\begin{abstract}
SUMMARY: CEA contralateral to an ICA occlusion is considered a surgical risk, and CAS may be an alternative for these patients. Our goal was to examine whether CAS improves cerebral hemodynamics on the treated side and on the side of the ICA occlusion, on the basis of measurement of CBF and CVR by using SPECT. The subjects were 8 patients who underwent contralateral CAS. Resting CBF and CVR to acetazolamide were measured by using ${ }^{123}$ I-IMP SPECT before and chronically (3-6 months) after CAS. Resting CBF was also measured immediately ( $<2$ hours) after CAS by using ${ }^{123}$ I-IMP SPECT. There were no significant differences in resting CBF in both hemispheres immediately after CAS. However, resting CBF and CVR both significantly increased in the chronic period in both hemispheres. Contralateral CAS in patients with ICA occlusion resulted in cerebral hemodynamic improvement on the treated side and on the side of ICA occlusion.
\end{abstract}

ABBREVIATIONS: CAS = carotid artery stenting; $C E A=$ carotid endarterectomy; $C V R=$ cerebrovascular reactivity; ${ }^{123}$-IMP $=$ iodine $123 \mathrm{~N}$-isopropyl-p-iodoamphetamine; $\mathrm{PaCO}_{2}$, = partial pressure of carbon dioxide

I

CA occlusion is an important cause of cerebral ischemia due to hemodynamic hypoperfusion. ${ }^{1}$ Severe stenosis in contralateral ICA occlusion may further impair cerebral hemodynamics and increase the risk of cerebral ischemic attack. ${ }^{2,3} \mathrm{CEA}$ of the carotid stenosis is often performed in such patients, and this procedure may have hemodynamic benefits. ${ }^{4-6}$ However, CEA for patients with contralateral ICA occlusion also has a high surgical risk. ${ }^{7-9}$ The reported efficacy and safety of CAS for severe stenosis contralateral to a carotid occlusion suggest that CAS may be a therapeutic alternative in these patients. ${ }^{10-15}$

In contrast to CEA, CAS is a relatively new technique and little is known about the hemodynamic consequences of contralateral CAS in patients with ICA occlusion. ${ }^{16-19}$ In this study, we used SPECT to investigate the immediate (within 2 hours after CAS) and chronic (3-6 months after CAS) hemodynamic effects of contralateral CAS in patients with ICA occlusion.

\section{CASE SERIES}

\section{Patients}

Eight consecutive patients with ICA occlusion who underwent contralateral CAS at our institution between January 2009 and

Received January 23, 2012; accepted after revision June 6.

From the Department of Neurosurgery, Yamaguchi University School of Medicine, Ube, Japan.

Please address correspondence to Fumiaki Oka, MD, PHD, Department of Neurosurgery, Yamaguchi University School of Medicine, 1-1-1, Minami-Kogushi, Ube,

Yamaguchi, 755-8505, Japan; e-mail: okafumiaki85@yahoo.co.jp

http://dx.doi.org/10.3174/ajnr.A3250
August 2011 were enrolled in this study. The mean age was 70 years (range, 60-81 years), and 7 subjects were men. Demographic data are shown in Table 1. Six patients were symptomatic, and 2 were asymptomatic. All 6 symptomatic patients had minor stoke or transient ischemic attack in the supply territory on the carotid occlusion side. In this study, the definition of "transient ischemic attack" was a brief episode of neurologic dysfunction caused by focal brain or retinal ischemia and without evidence of acute infarction on diffusion-weighted MR imaging. "Minor stroke" was defined as a neurologic dysfunction with evidence of acute infarction on diffusion-weighted MR imaging and a modified Rankin Scale score of $0-1$ on admission. All 8 patients underwent 4-vessel angiography before CAS, and ipsilateral ICA occlusion and contralateral severe $(>70 \%)$ ICA stenosis was confirmed. The degree of stenosis was determined by using the NASCET criteria. ${ }^{7}$ The average degree of stenosis was $81.5 \pm 5.4 \%$ (range, 72\%-90\%). During angiography, collateral flow on the side of the ICA occlusion was evaluated from the anterior communicating artery and posterior communicating artery. In all cases, collateral flow via the anterior communicating artery was recognized, and in 5 cases, collateral flow via the posterior communicating artery was also present.

\section{CBF Measurement}

CBF was evaluated by using SPECT, which was performed 3 times for each patient: within 2 weeks before, 2 hours after, and 3-6 months after CAS. Before and 3-6 months after CAS, resting CBF and CVR were measured in 1 session by using the dual-table au- 
Table 1: Patient and interventional characteristics

\begin{tabular}{|c|c|c|c|c|c|c|c|c|c|c|}
\hline Patient & $\begin{array}{l}\text { Age } \\
(y r) / \\
\text { Sex }\end{array}$ & Symptom & $\begin{array}{l}\text { Degree of } \\
\text { Stenosis } \\
(\%)\end{array}$ & $\begin{array}{c}\text { Collateral } \\
\text { Flow }\end{array}$ & DP & Stent & $\begin{array}{c}\text { Maximum } \\
\text { Balloon Size } \\
(\mathrm{mm})\end{array}$ & $\begin{array}{c}\text { Procedure Time } \\
\text { (Occlusion Time }^{\mathrm{a}} \text { ) } \\
\text { (min) }\end{array}$ & $\begin{array}{c}\text { Degree of } \\
\text { Stenosis } \\
\text { after CAS (\%) }\end{array}$ & $\begin{array}{l}\text { Clinical } \\
\text { Outcome } \\
\text { (mRS) }\end{array}$ \\
\hline 1 & $73 / \mathrm{M}$ & Asymptomatic & 86 & $\begin{array}{l}\text { AcomA + } \\
\text { PcomA + }\end{array}$ & CG & $P$ & 5.0 & $\begin{array}{c}1 \\
(8)\end{array}$ & 5 & 0 \\
\hline 2 & $68 / M$ & Minor stroke (hemodynamic) & 83 & $\begin{array}{l}\text { AcomA + } \\
\text { PcomA - }\end{array}$ & CG & $P$ & 4.0 & $\begin{array}{l}32 \\
(12)\end{array}$ & 5 & 0 \\
\hline 3 & $63 / F$ & Minor stroke (emboli) & 80 & $\begin{array}{l}\text { AcomA }+ \\
\text { PcomA }+\end{array}$ & AG & $P$ & 4.5 & 29 & 0 & 1 \\
\hline 4 & $60 / \mathrm{M}$ & Minor stroke (emboli) & 80 & $\begin{array}{l}\text { AcomA + } \\
\text { PcomA + }\end{array}$ & CG & $P$ & 5.0 & $\begin{array}{l}30 \\
\text { (11) }\end{array}$ & 0 & 1 \\
\hline 5 & $81 / \mathrm{M}$ & Asymptomatic & 83 & $\begin{array}{l}\text { AcomA + } \\
\text { PcomA - }\end{array}$ & CG & $P$ & 4.0 & $\begin{array}{l}25 \\
(7)\end{array}$ & 0 & 0 \\
\hline 6 & $69 / \mathrm{M}$ & TIA (hemodynamic) & 90 & $\begin{array}{l}\text { AcomA }+ \\
\text { PcomA }+\end{array}$ & FW & $\mathrm{CW}$ & 4.0 & 32 & 0 & 0 \\
\hline 7 & $80 / \mathrm{M}$ & Minor stroke (emboli) & 70 & $\begin{array}{l}\text { AcomA + } \\
\text { PcomA + }\end{array}$ & FW & $P$ & 5.0 & 31 & 5 & 0 \\
\hline 8 & $69 / \mathrm{M}$ & Minor stroke (hemodynamic) & 80 & $\begin{array}{l}\text { AcomA + } \\
\text { PcomA - }\end{array}$ & FW & $P$ & 4.5 & 40 & 0 & 0 \\
\hline
\end{tabular}

Note:-AG indicates AngioGuard XP; AcomA, anterior communicating artery; CG, carotid GuardWire; CW, carotid Wallstent; DP, distal protection device; FW, FilterWire EZ; mRS, modified Rankin Scale; P, Precise stent; PcomA, posterior communicating artery.

a The period from insertion of a guiding catheter until the end of the procedure.

b The period from inflation to deflation of a distal occlusion balloon in cases in which a Carotid GuardWire was used.

toradiographic method and dual administration of ${ }^{123}$ I-IMP, as described in detail elsewhere. ${ }^{20}$ For the dual-table autoradiographic method, 2 dynamic scans were acquired in quick succession, with a 2-minute interval between scans. The first scan covered the initial period from 0 to 28 minutes, and the second scan was acquired from 30 to 58 minutes. At 4 minutes per frame, 7 frames covered each of the 2 dynamic scanning periods. ${ }^{123}$ I-IMP (167 MBp) was intravenously infused for 1 minute at a constant rate. For SPECT with drug challenge, acetazolamide (Diamox; 17 $\mathrm{mg} / \mathrm{kg} ; 1000 \mathrm{mg}$ maximum) was administered intravenously 20 minutes after the first ${ }^{123} \mathrm{I}$-IMP injection and thus 10 minutes before the second ${ }^{123}$ I-IMP injection. CVR was calculated as follows: $\mathrm{CVR}=100 \times($ Diamox $\mathrm{CBF}-$ resting $\mathrm{CBF}) /$ resting $\mathrm{CBF}$. Blood was sampled from the antecubital artery 10 minutes after the injection. In the SPECT study performed within 2 hours after CAS, only resting CBF was measured by using the autoradiography method with a single administration of ${ }^{123}$ I-IMP and a single scan.

The resolution of the SPECT system was $10.4 \mathrm{~mm}$ at full width at half maximum. The system consisted of a 3-headed $\gamma$ camera GCA-9300A/HF (Toshiba, Tokyo, Japan) equipped with low-energy high-resolution fan-beam collimators and a processing computer GMS-5500A/DI (Toshiba). Projection data were obtained from each camera in 10 rotations and with triple photopeaks for triple energy window scatter correction.

\section{Image Analysis}

Hemispheric CBF was measured by using an automated regionof-interest analysis, as described in detail elsewhere. ${ }^{21}$ Before the analysis, we constructed a VOI template generated by NEUROSTAT (http://128.95.65.28/ Download/) to determine the ROIs, which were all located in the hemisphere. The VOI template was modified in size and shape on the basis of individual SPECT images to determine the region-of-interest boundaries. First, a SPECT image was anatomically standardized by using NEUROSTAT to obtain information for voxel transformation. Using this information and inverse transformation, we modified the VOI template to fit the SPECT image. The inverse transformed VOI templates were then extracted from each section to determine the ROIs. Finally, the determined ROIs were positioned on the individual SPECT images. The hemispheric region of interest at the level of the basal ganglia was used for analysis.

\section{Endovascular Technique}

Before the procedure, all patients were premedicated for at least 72 hours with 2 antiplatelet agents chosen from aspirin (100 mg), clopidogrel (75 mg), and cilostazol (200 mg). All procedures were performed with the patient under local anesthesia. After diagnostic angiography, heparin was intravenously administered to maintain an activated clotting time for 280 seconds. An 8 F guiding catheter was advanced to the affected common carotid artery. Distal protection devices were used in all cases to avoid distal emboli during the procedure. A carotid GuardWire (Medtronic, Minneapolis, Minnesota) was used in 4 cases; a FilterWire EZ (Boston Scientific, Natick, Massachusetts), in 3 cases; and an AngioGuard XP (Cordis, Miami Lakes, Florida), in 1 case. In the cases in which a carotid GuardWire was used, we inflated the distal balloon for 1 minute before the procedure to confirm tolerability to transient occlusion, and no ischemic symptoms were observed. Predilation was performed with a 3.0- to 3.5- $\mathrm{mm}$ angioplasty balloon (Sterling; Boston Scientific), and a self-expandable stent of appropriate size was deployed. A Precise stent (Cordis) was used in 7 cases, and a carotid Wallstent (Boston Scientific) was used in 1 case. Postdilation was performed with a high pressure 4.0- to 5.0-mm semicompliant angioplasty balloon (Aviator; Cordis). Demographic data are shown in Table 1.

\section{Statistical Analysis}

Descriptive data are presented as means. A paired $t$ test was used to compare paired data (hematocrit, $\mathrm{PaCO}_{2}$, mean blood pressure, resting CBF, and CVR) between the preoperative and 2 postoperative SPECT studies. Differences were deemed to be statisti- 
Table 2: Physiologic data before and after carotid artery stenting

\begin{tabular}{|c|c|c|c|}
\hline Parameter & $\begin{array}{c}\text { Before } \\
\text { CAS }\end{array}$ & $\begin{array}{c}\text { After CAS } \\
(<2 \mathrm{~h})\end{array}$ & $\begin{array}{c}\text { After CAS } \\
(<3 \mathrm{mo})\end{array}$ \\
\hline & $5.0 \pm 3.3$ & $35.9 \pm 3.1$ & \\
\hline $\mathrm{PaCO}_{2}(\mathrm{~mm} \mathrm{Hg})$ & $36.4 \pm$ & $38.3 \pm 3.6$ & $37.1 \pm 2.9$ \\
\hline Mean arterial pressure $(\mathrm{mm} \mathrm{Hg})$ & $104 \pm 9$ & $86 \pm 17.6^{\mathrm{a}}$ & $89 \pm 9.2^{\mathrm{a}}$ \\
\hline
\end{tabular}

a $P<.05$ vs preoperative data.

cally significant if the probability value was less than .05. All calculations were performed by using StatView Version 5.0 software (SAS Institute, Cary, North Carolina).

\section{RESULTS}

CAS was successfully performed in all patients, and no complications occurred in this series. No cerebral ischemic attacks have occurred in either cerebral hemisphere during a mean follow-up period of 24 months. Physiologic data (Table 2) showed that hematocrit and $\mathrm{PaCO}_{2}$ were stable between measurements, but blood pressure was significantly reduced immediately and chronically after CAS. Resting CBF (Table 3) was unchanged in both hemispheres immediately after CAS (Table 3) but was significantly increased in both hemispheres in the chronic period. CVR also significantly increased in both hemispheres chronically after CAS (Table 3).

To illustrate the results in more detail, we describe a representative case of a 68-year-old man (patient 2 of Table 1) who had transient left hemiparesis and in whom fresh infarction in the right frontal lobe (watershed area) was detected on MR imaging. MR angiography revealed occlusion of the right ICA and severe stenosis of the left ICA. One month after onset, CAS for the left ICA was performed successfully. Transient hypotension occurred for a few days after the procedure, but the patient was finally discharged home with no neurologic deficits. Before CAS, resting CBF and CVR were $25.68 \mathrm{~mL} / 100 \mathrm{~g} / \mathrm{min}$ and $5.9 \%$, respectively, on the CAS side and $24.58 \mathrm{~mL} / 100 \mathrm{~g} / \mathrm{min}$ and $-6.3 \%$, respectively, on the side of ICA occlusion. Resting CBF decreased slightly in both hemispheres $(20.7 \mathrm{~mL} / 100 \mathrm{~g} / \mathrm{min}$ on the treated side and $19.71 \mathrm{~mL} / 100 \mathrm{~g} / \mathrm{min}$ on the ICA occluded side) immediately after CAS, but no ischemic symptoms were observed and no new infarct lesion was seen on MR imaging after CAS. Five months after CAS, resting CBF and CVR had increased in both hemispheres, to $27.27 \mathrm{~mL} / 100 \mathrm{~g} / \mathrm{min}$ and $33.1 \%$, respectively, on the treated side and to $26.22 \mathrm{~mL} / 100 \mathrm{~g} / \mathrm{min}$ and $15.8 \%$, respectively, on the ICA occluded side (Fig 1).

\section{DISCUSSION}

In this study, we investigated hemodynamic changes immediately and chronically after contralateral CAS in patients with a preexisting ICA occlusion. There were no significant differences in resting $\mathrm{CBF}$ in both hemispheres immediately after CAS. However, resting $\mathrm{CBF}$ and CVR both significantly increased in the chronic period on the side of CAS and on the side of the ICA occlusion.

Two opposite pathologic conditions may occur immediately after CAS: hyperperfusion and hemodynamic ischemia. "Cerebral hyperperfusion syndrome," which is defined as a major increase in ipsilateral CBF to well above the metabolic demands of the brain tissue following the repair of carotid artery stenosis, ${ }^{22,23}$ is a rare but potentially catastrophic complication after CEA or CAS. ${ }^{24-32}$ The mechanism remains unclear, but preoperative impairment of autoregulation due to chronic hypoperfusion resulting from contralateral ICA occlusion is one of the risk factors. ${ }^{32-34}$ To prevent this syndrome, strict control of blood pressure during the postoperative period has been emphasized in many reports. ${ }^{22-24,33}$ Hyperperfusion did not occur in any of our patients; however, the possible occurrence of this condition should be recognized.

Conversely, too much reduction of blood pressure can lead to hemodynamic ischemia, especially on the side of ICA occlusion. Transient bradycardia and hypotension due to carotid artery baroreceptor damage often occur during CAS. ${ }^{35-37}$ On the basis of our results, blood pressure significantly decreased immediately after CAS, and it is possible that an abrupt decrease of blood pressure might lead to cerebral ischemia. However, we found that resting CBF did not change significantly in both hemispheres and no ischemic complications occurred. Even in the situation of hypotension associated with CAS, our data suggest that the decrease in CBF on the side of ICA occlusion can be minimized with the help of cerebral autoregulation or collateral cross-flow from the CAS side. In other words, if collateral flow from the anterior communicating artery is absent, careful management of blood pressure might be required.

In contrast to the situation immediately after CAS, resting CBF and CVR significantly increased on the CAS and ICA occlusion sides in the chronic period. Several studies have found hemodynamic benefits of contralateral CEA in patients with ICA occlusion. ${ }^{5,6}$ In contrast, CAS is a relatively new technique, and only a few small studies have evaluated the hemodynamic consequences in similar patients. ${ }^{16-19}$ Two previous studies are consistent with our results. In a study of 5 patients, Kataoka et $\mathrm{al}^{17}$ examined changes of resting CBF and CVR by using SPECT from before to approximately 1 week after CAS. Similar improvements of resting CBF and CVR were observed on both sides, even though postoperative SPECT was performed much earlier than in our study. ${ }^{17}$ These results suggest that hemodynamic changes may occur within 1 week after the procedure. In a study of 74 patients (24 of whom had contralateral ICA occlusion), Trojanowska et $\mathrm{al}^{18}$ measured cerebral perfusion changes with time after CAS on the basis of CT perfusion imaging and reported similar hemodynamic improvements in both hemispheres in patients with contralateral ICA occlusion at 3 days and 6 months after the procedure. In a study of 21 patients ( 9 of whom had bilateral ICA stenosis or occlusion), Tang et $\mathrm{al}^{19}$ measured arterial blood pressure and cerebral blood flow velocity of the middle cerebral artery by using transcranial Doppler from 10 minutes before to 24 hours after CAS. These data showed improvement of dynamic cerebral autoregulation on the CAS side, but not on the contralateral nonstented side. ${ }^{19}$ This discrepancy with the current study and other previous studies may be due to the difference in the period after the procedure before measurement, because more time may be required to obtain an effect on the nonstented side, and also differences in patient characteristics, because cases with both ICA occlusion and stenosis were included in Tang et al. ${ }^{19}$

In patients with carotid artery occlusion, decreased resting CBF and CVR measured by SPECT are risk factors for future 
Table 3: Hemodynamic changes in both cerebral hemispheres before, immediately after, and chronically after carotid artery stenting

\begin{tabular}{|c|c|c|c|c|c|c|c|c|c|c|}
\hline \multirow[b]{3}{*}{ Patient } & \multicolumn{5}{|c|}{ Side of CAS } & \multicolumn{5}{|c|}{ Side of ICA Occlusion } \\
\hline & \multicolumn{3}{|c|}{ Resting CBF (mL/100 g/min) } & \multicolumn{2}{|c|}{ CVR (\%) } & \multicolumn{3}{|c|}{ Resting CBF (mL/100 g/min) } & \multicolumn{2}{|c|}{ CVR (\%) } \\
\hline & $\begin{array}{l}\text { Before } \\
\text { CAS }\end{array}$ & $\begin{array}{l}\text { After CAS } \\
(<2 \mathrm{~h})\end{array}$ & $\begin{array}{c}\text { After CAS } \\
\text { (3-6 mo) }\end{array}$ & $\begin{array}{l}\text { Before } \\
\text { CAS }\end{array}$ & $\begin{array}{c}\text { After CAS } \\
\text { (3-6 mo) }\end{array}$ & $\begin{array}{l}\text { Before } \\
\text { CAS }\end{array}$ & $\begin{array}{l}\text { After CAS } \\
(<2 \mathrm{~h})\end{array}$ & $\begin{array}{l}\text { After CAS } \\
(3-6 \mathrm{mo})\end{array}$ & $\begin{array}{l}\text { Before } \\
\text { CAS }\end{array}$ & $\begin{array}{c}\text { After CAS } \\
\text { (3-6 mo) }\end{array}$ \\
\hline 1 & 32.8 & 31.0 & 40.3 & 6.0 & 19.6 & 31.9 & 30.4 & 38.5 & -1.1 & -1.2 \\
\hline 2 & 25.7 & 20.7 & 27.3 & 5.9 & 33.1 & 24.6 & 19.7 & 26.2 & -6.3 & 15.8 \\
\hline 3 & 27.6 & 23.2 & 27.8 & 30.0 & 39.2 & 23.4 & 19.4 & 23.3 & 17.8 & 32.4 \\
\hline 4 & 24.4 & 30.9 & 29.5 & 7.3 & 44.4 & 19.7 & 24.2 & 23.3 & 10.3 & 36.2 \\
\hline 5 & 25.3 & 25.6 & 26.2 & 48.4 & 54.0 & 19.2 & 21.5 & 23.1 & 3.4 & 5.0 \\
\hline 6 & 27.9 & 27.9 & 34.5 & 26.6 & 59.9 & 26.0 & 27.0 & 32.7 & 20.0 & 18.0 \\
\hline 7 & 31.3 & 29.3 & 32.5 & 30.1 & 28.2 & 32.8 & 31.3 & 30.6 & 16.7 & 24.9 \\
\hline 8 & 18.5 & 17.0 & 19.9 & 38.0 & 51.6 & 18.9 & 16.9 & 20.2 & 33.2 & 45.2 \\
\hline Mean & $26.7 \pm 4.1$ & $25.7 \pm 4.8$ & $29.7 \pm 5.7^{\mathrm{a}}$ & $24.0 \pm 15.0$ & $41.2 \pm 12.9^{\mathrm{a}}$ & $24.6 \pm 5.1$ & $23.8 \pm 5.0$ & $27.2 \pm 5.8^{\mathrm{a}}$ & $11.8 \pm 12.0$ & $22.0 \pm 14.7^{a}$ \\
\hline
\end{tabular}

${ }^{a} P<.05$ vs preoperative data.
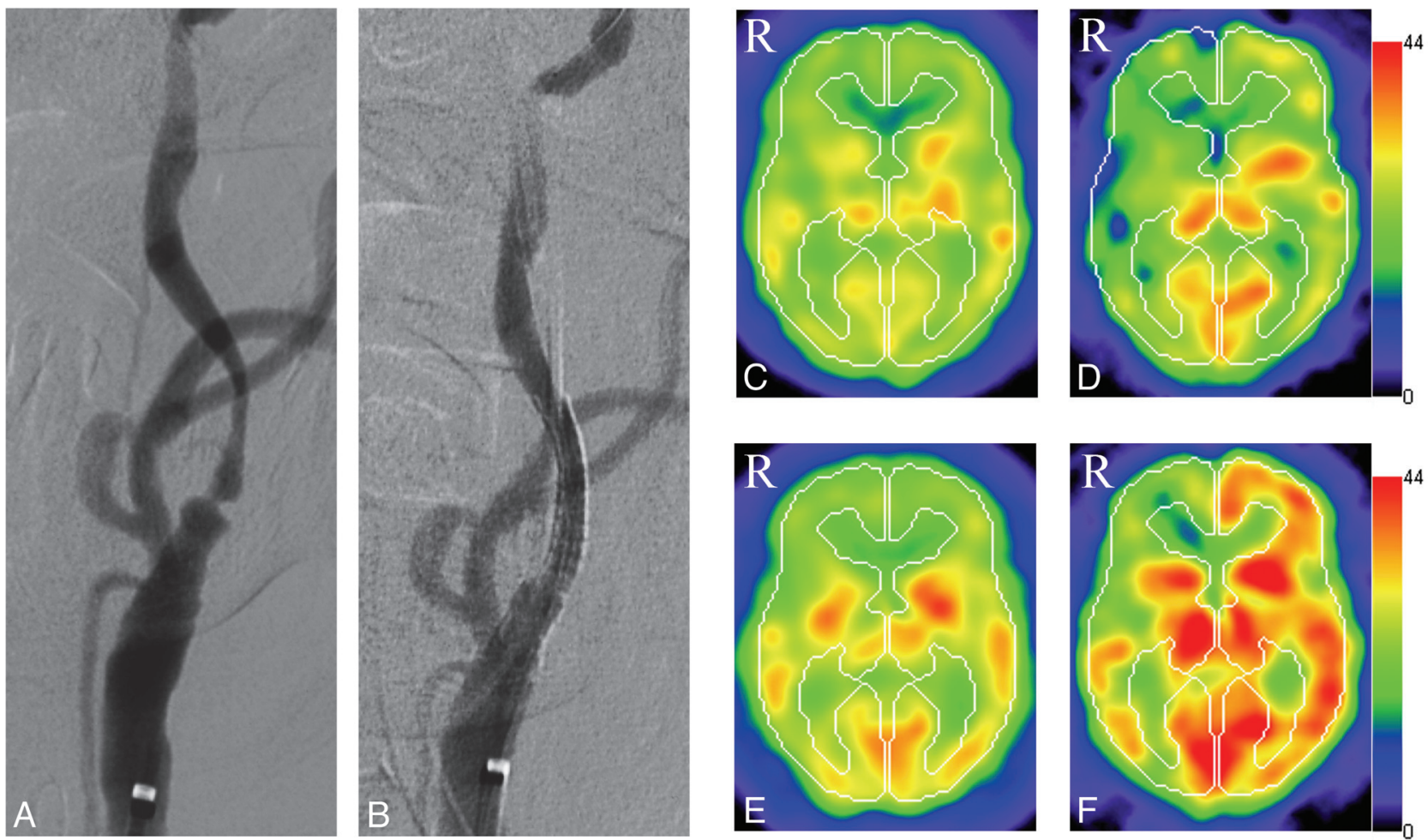

FIG 1. Images obtained in a representative case. A, A preoperative left common carotid artery angiogram shows severe ICA stenosis (anteroposterior view). B, Left CAS was performed and a postoperative angiogram reveals no significant residual stenosis (anteroposterior view). $C$ and $D$, Preoperative SPECT shows hypoperfusion $(C)$ and low cerebrovascular reactivity $(D)$ in both hemispheres. In the right hemisphere, a steal phenomenon is detected $(D)$. E and $F$, Postoperative SPECT obtained 3 months after CAS. The examination demonstrates increased resting CBF $(E)$ and cerebrovascular reactivity $(F)$ on both the ipsilateral and the contralateral carotid occluded sides.

ischemic stroke. ${ }^{38,39}$ However, the effectiveness of improved cerebral hemodynamics after surgical revascularization for preventing ischemic stroke is uncertain. In the recent Carotid Surgery Study Randomized Trial, extracranial-intracranial bypass surgery did not show an additional benefit over medical therapy for prevention of recurrent stroke, despite improvement of cerebral hemodynamics in the surgery group. ${ }^{40}$ However, in patients with ICA occlusion and contralateral ICA stenosis, cerebral hemodynamics may be more disturbed, and higher risks of ischemic stroke have been reported for both symptomatic and asymptomatic patients. ${ }^{2,3,41,42}$ A number of studies have shown that contralateral CEA in patients with ICA occlusion has a long-term effect on prevention of stroke on the side of endarterectomy and on the side of ICA occlusion, which is explained by improvement of cerebral hemodynamics on the side of ICA occlusion; however, among these studies, only the NASCET study was a randomized trial. ${ }^{5,6,41,43,44}$ After CAS, a similar improvement was seen in our patients and in previous studies. ${ }^{17,18}$ Therefore, from a hemodynamic point of view, CAS also seems to be effective for prevention of ischemic stroke on the side of ICA occlusion.

In cases of ICA occlusion with contralateral ICA stenosis, revascularization by CEA for ICA stenosis has often been performed. ${ }^{5,6,41,43,44}$ However, CEA contralateral to ICA occlusion is considered to have a higher surgical risk due to reduction of collateral flow during carotid clamping. ${ }^{8,9}$ Routine or selective use of an intraluminal shunt during CEA has been reported to be effective for avoidance of this risk. ${ }^{45,46} \mathrm{CAS}$ also requires shorter temporary occlusion during the procedure. On the basis of a system- 
atic review of 206 independent studies of 54,713 patients who received CAS, Touzé et $\mathrm{al}^{47}$ found that CAS contralateral to carotid occlusion does not increase the operative risk. Several other studies have also shown the safety and effectiveness of CAS contralateral to carotid occlusion. ${ }^{10-15}$ In our cases, there were neither complications nor recurrent ischemic attacks during and after CAS. Thus, although CAS has yet to be shown to have safety equivalent to that of CEA, contralateral CAS may be a good option in patients with ICA occlusion.

There are some limitations of this study that require discussion. First, we used the region-of-interest method to analyze CBF. This method is widely used, but it does not include the whole brain. Second, we used SPECT, whereas the most reliable method for hemodynamic assessment is PET. It has been reported that decreased resting CBF and the CVR to acetazolamide are related to the increased oxygen extraction fraction assessed by PET, and this could be useful for the screening of patients with misery perfusion. $^{48}$

\section{CONCLUSIONS}

We reported hemodynamic changes with time after contralateral CAS for severe ICA stenosis in patients with ICA occlusion. Immediately after CAS, CBF did not change significantly in both hemispheres, and neither hyperperfusion nor hemodynamic ischemia occurred. Chronically after CAS, cerebral hemodynamic improvements were seen on both the treated side and the side of the ICA occlusion. From a hemodynamic perspective, CAS was effective for preventing ischemic attacks in both hemispheres in our patients.

\section{REFERENCES}

1. Powers WJ. Cerebral hemodynamics in ischemic cerebrovascular disease. Ann Neurol 1991;29:231-40

2. Weiller C, Ringelstein EB, Reiche W, et al. Clinical and hemodynamic aspects of low flow infarcts. Stroke 1991;22:1117-23

3. Klijn CJ, Kappelle LJ, Tulleken CAF, et al. Symptomatic carotid artery occlusion: a reappraisal of hemodynamic factors. Stroke 1997;28:2084-93

4. Visser GH, van Huffelen AC, Wieneke GH, et al. Bilateral increase in $\mathrm{CO}_{2}$ reactivity after unilateral carotid endarterectomy. Stroke 1997;28:899-905

5. Rutgers DR, Klijn CJ, Kappelle LJ, et al. Sustained bilateral hemodynamic benefit of contralateral carotid endarterectomy in patients with symptomatic internal carotid artery occlusion. Stroke 2001;32:728-34

6. Baracchini C, Meneghetti G, Manara R, et al. Cerebral hemodynamics after contralateral carotid endarterectomy in patients with symptomatic and asymptomatic carotid occlusion: a 10-year follow up. J Cereb Blood Flow Metab 2006;26:899-905

7. Beneficial effect of carotid endarterectomy in symptomatic patients with high-grade stenosis: North American Symptomatic Carotid Endarterectomy Trial Collaborators. $N$ Engl $J$ Med 1991;325:445-53

8. Maatz W, Kohler J, Botsios S, et al. Risk of stroke for carotid endarterectomy patients with contralateral carotid occlusion. Ann Vasc Surg 2008;22:45-51

9. Menyhei G, Bjorck M, Beiles B, et al. Outcome following carotid endarterectomy: lessons learned from a large international vascular registry. Eur J Vasc Endovasc Surg 2011;41:735-40

10. Mathur A, Roubin GS, Gomez CR, et al. Elective carotid artery stenting in the presence of contralateral occlusion. Am J Cardiol 1998;81:1315-17
11. Mericle RA, Kim SH, Lanzino G, et al. Carotid artery angioplasty and use of stents in high-risk patients with contralateral occlusions. J Neurosurg 1999;90:1031-36

12. Sabeti S, Schillinger M, Miekusch W, et al. Contralateral high-grade carotid artery stenosis or occlusion is not associated with increased risk for poor neurologic outcome after elective carotid artery stent placement. Radiology 2004;230:70-76

13. González A, González-Marcos JR, Martínez E, et al. Safety and security of carotid artery stenting for severe stenosis with contralateral occlusion. Cerebravasc Dis 2005;20(suppl 2):123-28

14. Gandini R, Spinelli A, Fabiano S, et al. Carotid artery stenting with filter protection in high-risk patients showing severe electroencephalographic alterations during carotid endarterectomy. J Endovasc Ther 2006;13:451-56

15. Mehta RH, Zahn R, Hochadel M, et al. Effectiveness and safety of carotid artery stenting for significant carotid stenosis in patients with contralateral occlusion (from the German ALKK-CAS registry experience). Am J Cardiol 2009;104:725-31

16. McCleary AJ, Nelson M, Dearden NM, et al. Cerebral haemodynamics and embolization during carotid angioplasty in high-risk patients. Br J Surg 1998;85:771-74

17. Kataoka T, Hyougo T, Hayase K, et al. Cerebral blood flow change before and after carotid artery angioplasty and stenting (CAS) in cases with contralateral carotid artery occlusion. Interv Neuroradiol 2006;12(suppl 1):201-04

18. Trojanowska A, Drop A, Jargiello T, et al. Changes in cerebral hemodynamics after carotid stenting: evaluation with $\mathrm{CT}$ perfusion studies. J Neuroradiol 2006;33:169-74

19. Tang SC, Huang YW, Shieh JS, et al. Dynamic cerebral autoregulation in carotid stenosis before and after carotid stenting. J Vasc Surg 2008;48:88-92

20. Kim KM, Watabe H, Hayashi T, et al. Quantitative mapping of basal and vasoreactive cerebral blood flow using split-dose 123I-iodoamphetamine and single photon emission computed tomography. Neuroimage 2006;33:1126-35

21. Ogura T, Hida K, Masuzuka T, et al. An automated ROI setting method using NEUROSTAT on cerebral blood flow SPECT images. Ann Nucl Med 2009;23:33-41

22. Sundt TM Jr, Sharbrough FW, Piepgras DG, et al. Correlation of cerebral blood flow and electroencephalographic changes during carotid endarterectomy, with results of surgery and hemodynamics of cerebral ischemia. Mayo Clin Proc 1981;56:533-43

23. Piepgras DG, Morgan MK, Sundt TM Jr, et al. Intracranial hemorrhage after carotid endarterectomy. J Neurosurg 1988;68:532-56

24. Solomon RA, Loftus CM, Quest DO, et al. Incidence and etiology of intracerebral hemorrhage following carotid endarterectomy. J Neurosurg 1986;64:29-34

25. Jansen C, Sprengers AM, Moll FL, et al. Prediction of intracerebral hemorrhage after carotid endarterectomy by clinical criteria and intraoperative transcranial Doppler monitoring. Eur J Vasc Surg 1994;8:220-25

26. Ouriel K, Shortell CK, Illig KA, et al. Intracerebral hemorrhage after carotid endarterectomy: incidence, contribution to neurologic morbidity, and predictive factors. J Vasc Surg 1999;29:82-87, discussion 87-89

27. McCabe DJ, Brown MM, Clifton A. Fatal cerebral reperfusion hemorrhage after carotid stenting. Stroke 1999;30:2483-86

28. Meyers PM, Higashida RT, Phatouros CC, et al. Cerebral hyperperfusion syndrome after percutaneous transluminal stenting of the craniocervical arteries. Neurosurgery 2000;47:335-43

29. Henderson RD, Phan TG, Piepgras DG, et al. Mechanism of intracerebral hemorrhage after carotid endarterectomy. I Neurosurg 2001;95:964-69

30. Abou-Chebl A, Yadav JS, Reginelli JP, et al. Intracranial hemorrhage and hyperperfusion syndrome following carotid artery stenting: risk factors, prevention, and treatment. J Am Coll Cardiol 2004;43:1596-601 
31. van Mook WN, Rennenberg RJ, Schurink GW, et al. Cerebral hyperperfusion syndrome. Lancet Neurol 2005;4:877-88

32. Moulakakis KG, Mylonas SN, Sfyroeras GS, et al. Hyperperfusion syndrome after carotid revascularization. J Vasc Surg 2009;49: $1060-68$

33. Reigel MM, Hollier LH, Sundt TM Jr, et al. Cerebral hyperperfusion syndrome: a cause of neurologic dysfunction after carotid endarterectomy. J Vasc Surg 1987;5:628-34

34. Ascher E, Markevich N, Schtzer RW, et al. Cerebral hyperperfusion syndrome after carotid endarterectomy: predictive factors and hemodynamic changes. J Vasc Surg 2003;37:769-77

35. Mendelsohn FO, Weissman NJ, Lederman RJ, et al. Acute hemodynamic changes during carotid artery stenting. Am J Cardiol 1998;82:1077-81

36. Qureshi AI, Luft AR, Sharma M, et al. Frequency and determinants of postprocedural hemodynamic instability after carotid angioplasty and stenting. Stroke 1999;30:2086-93

37. McKevitt FM, Sivaguru A, Venables GS, et al. Effect of treatment of carotid artery stenosis on blood pressure: a comparison of hemodynamic disturbances after carotid endarterectomy and endovascular treatment. Stroke 2003;34:2576-81

38. Kuroda S, Houkin K, Kamiyama H, et al. Long-term prognosis of medically treated patients with internal carotid or middle cerebral artery occlusion: can acetazolamide test predict it? Stroke 2001;32:2110-16

39. Ogasawara K, Ogawa A, Yoshimoto T. Cerebrovascular reactivity to acetazolamide and outcome in patients with symptomatic internal carotid or middle cerebral artery occlusion: a xenon-133 singlephoton emission computed tomography study. Stroke 2002;33: 1857-62

40. Powers WJ, Clarke WR, Grubb RL Jr, et al. Extracranial-intercranial bypass surgery for stroke prevention in hemodynamic cerebral ischemia: the Carotid Surgery Study Randomized Trial. JAMA 2011;306:1983-92

41. Gasecki AP, Eliasziw M, Ferguson GG, et al. Long-term prognosis and effect of endarterectomy in patients with symptomatic severe carotid stenosis and contralateral carotid stenosis or occlusion: results from NASCET. J Neurosurg 1995;83:778-82

42. AbuRahma AF, Metz MJ, Robinson PA. Natural history of $\geq \mathbf{6 0 \%}$ asymptomatic carotid stenosis in patients with contralateral carotid occlusion. Ann Surg 2003;238:551-61, discussion 561-62

43. Jacobowitz GR, Adelman MA, Riles TS, et al. Long-term follow-up of patients undergoing carotid endarterectomy in the presence of a contralateral occlusion. Am J Surg 1995;170:165-67

44. AbuRahma AF, Robinson P, Holt AM, et al. Perioperative and late stroke rates of carotid endarterectomy contralateral to carotid artery occlusion: results from a randomized trial. Stroke 2000;31: 1566-71

45. Cinar B, Goksel OS, Karatepe C, et al. Is routine intravascular shunting necessary for carotid endarterectomy in patients with contralateral occlusion? A review of 5-year experience of carotid endarterectomy with local anaesthesia. Eur J Vasc Endovasc Surg 2004;28:494-99

46. Goodney PP, Wallaert JB, Scali ST, et al. Impact of practice pattern in shunt use during carotid endarterectomy with contralateral carotid occlusion. J Vasc Surg 2012;55:61-71.e1

47. Touzé E, Trinquart L, Chatellier G, et al. Systematic review of the perioperative risk of stroke or death after carotid angioplasty and stenting. Stroke 2009;40:e683-e93

48. Imaizumi M, Kitagawa K, Hashikawa K, et al. Detection of misery perfusion with split-dose 123I-iodoamphetamine single-photonemission computed tomography in patients with carotid occlusive diseases. Stroke 2002;33:2217-23 